\title{
The Fate of Mud Nourishment in Response to Short-Term Wind Forcing
}

\author{
Kirstin Schulz $^{1}$ (I) $\cdot$ Knut Klingbeil $^{2}$. Claudia Morys ${ }^{3}$. Theo Gerkema ${ }^{4}$
}

Received: 25 March 2019 / Revised: 14 May 2020 / Accepted: 20 May 2020

(C) The Author(s) 2020, corrected publication 2021

\begin{abstract}
In this study, results from a realistic 3D hydrodynamic and sediment transport model, applied to a channel in the Dutch Wadden Sea, are analyzed in order to assess the effect of short-term wind forcing, the impact of fresh water effects, and the variability induced by the spring-neap cycle on the transport of suspended sediment. In the investigated region, a pilot study for sediment nourishment, the so-called Mud Motor, is executed. This project aims for the beneficial re-use of dredged harbor sediments through the disposal of these sediments at a location where natural currents are expected to transport them toward a nearby salt marsh area. The model results presented in this study advance the understanding of the driving forces that determine sediment transport in shallow, near-coastal zones, and can help to improve the design of the Mud Motor. In the investigated channel, which is oriented parallel to the coastline, tidal asymmetries generally drive a transport of sediment in flood direction. It was found that already moderate winds along the channel axis reverse (wind in ebb direction), or greatly enhance this transport, up to an export of sediment over the adjacent water shed (wind in flood direction). The most beneficial wind conditions (moderate westerly winds) can cause an accumulation of more than $90 \%$ of the initial 200 tons sediment pool on the intertidal area; during less favorable conditions (northeasterly winds), less than a third of the dumped sediment is transported onto the mudflat. On-shore winds induce a transport toward the coast. Surprisingly, sediment pathways are only sensitive to the exact disposal location in the channel during wind conditions that counteract the tidally driven transport, and freshwater effects play no significant role for the dispersal of sediment.
\end{abstract}

Keywords Mud motor $\cdot$ Wadden sea $\cdot$ Numerical model $\cdot$ Sediment transport

\section{Introduction}

Coastal wetlands, such as salt marshes, provide unique habitats for numerous species and protect the shore from erosion

Communicated by Stephen G. Monismith

Kirstin Schulz

kirstin.schulz@awi.de

1 Alfred-Wegener-Institut Helmholtz-Zentrum für Polar - und Meeresforschung, Bremerhaven, Germany

2 Department of Physical Oceanography and Instrumentation, Leibniz Institute for Baltic Sea Research Warnemünde (IOW), Seestraße 15, 18119 Warnemünde, Germany

3 Faculty of Science, Department of Ecology, Environment and Plant Sciences, Stockholm University, SE-106 91 Stockholm, Sweden

4 NIOZ Netherlands Institute for Sea Research, Department of Estuarine and Delta Systems, and Utrecht University, P.O. Box 140, 4400 AC Yerseke, The Netherlands by dampening wave energy. As their existence is closely linked to the tidal inundation, the rising sea levels will likely result in an extensive loss of wetlands over the next century (Donnelly and Bertness 2001). Consequently, coastal authorities have been searching for ways to protect these habitats. Coastal engineering techniques for shore protection and land reclamation have advanced in the past decades: The traditional approach of building hard structures, like breakwaters and groynes, to counteract natural forces often entailed adverse environmental effects in the long term. Shore nourishment is considered a better and more environmentally acceptable alternative and nowadays often the principal option for coastal protection (Hanson et al. 2002; Hamm et al. 2002; Nordstrom 2005). Furthermore, shore nourishment can contribute to the preservation of coastal wetlands, as the vertical and lateral growth of salt marshes that is needed to keep up with sea level rise is, among other factors, determined by the available supply of sediment for accretion on the marsh.

A pilot study for sediment nourishment, referred to as the Mud Motor, was started in the Dutch Wadden Sea in 2016. 
Within this project, fine sediments from maintenance harbor dredging are deposited at a location close to the shore, where the tidal flow is expected to disperse the material and thereby facilitate the growth of nearby salt marsh zones (van Eekelen et al. 2016; Baptist et al. 2019). In this way, the negative ecological impact of disposing sediment directly on the salt marsh is reduced (Speybroeck et al. 2006), and the dredged harbor sediment is re-used in a beneficial way.

The concept of the Mud Motor is gaining international attention and was recently included in the "Engineering with Nature Atlas," published by the US Army Corps of Engineers (see www.engineeringwithnature.org; Bridges (2018)).

The design of the Mud Motor includes frequent sediment disposals, which provides a flexibility that can be used to advantage: The exact disposal location for the dredged sediment can be changed anytime to minimize the sailing time for the dredging ship, and to maximize the effectiveness of the nourishment, depending on the circumstances. This requires detailed knowledge about the local driving forces for sediment transport at spatial and temporal scales that can only be achieved by a numerical model.

Complex topography and the combination of different driving forces pose a challenge to understanding pathways of sediment transport in near-coastal areas. Previous studies showed that the transport of suspended sediment in the Dutch Wadden Sea is episodic in nature and mainly determined by the contemporaneous wind conditions (Sassi et al. 2015; Becherer et al. 2016). Another study found that freshwater discharge influences the hydrodynamic properties in this region (Schulz and Gerkema 2018), with possible implications for sediment transport. The relative influence of individual driving forces to sediment transport is still an open question, and can hardly be answered from observations alone. The aim of this study is to set up and evaluate a numerical model for the Mud Motor region to assess the effect of short-term wind forcing, the impact of freshwater effects, the variability induced by the springneap cycle, and the influence of a variable disposal location on sediment transport. This way, an efficient strategy to economically improve the nourishment can be developed.

The core question of this paper is how sensitive the pathway of suspended sediment is to its initial position, depending on external conditions. This question borders on the nature of the transport routes in tidal basins. Ridderinkhof and Zimmerman (1992) already found that (even in the absence of wind) the combination of tidal and residual flows in tidal basins leads to chaotic pathways of tracers. The hallmark of such chaotic behavior is the sensitivity on initial conditions. Hence, the question naturally arises how sensitive the fate of sediment is to its initial deposition location, especially in the presence of wind.
The complex sedimentary and erosion processes on the salt marsh are subject to other studies and will not be investigated here, as the focus of this study is on the pathways inside the tidal basin before potential sedimentation on the marshes.

The manuscript is structured as follows: In sections "Study Site" and "Methods", a description of the Mud Motor area and the local wind climate are given, and the numerical model and its validation are described. In section "Results", the model results on sediment transport are presented. In Sections "Discussion" and "Conclusions", the limitations of the model, the fate of sediment nourishment under variable conditions and disposal locations, and the economical aspects of the Mud Motor project are discussed and put into perspective.

\section{Study Site}

\section{The Pilot Project}

The pilot study of the Mud Motor started in 2016 and is conducted in the Western Dutch Wadden Sea, near the port of Harlingen (see Fig. 1). This port was chosen as maintenance dredging to safeguard navigation produces an annual volume of approximately 1.3 million $\mathrm{m}^{3}$ mainly finegrained sediment that used to be disposed in the Wadden Sea in the vicinity of the harbor. It is expected that a considerable amount of this sediment recirculates into the harbor, which is economically inefficient (van Eekelen et al. 2016). A small channel parallel to the coastline (the Kimstergat) forms a connection between the port and a shallow intertidal area northeast, bordered by a narrow rim of salt marshes at the landward side (see Fig. 1B). Due to its limited width, the salt marsh is lacking floral diversity and breeding birds (Baptist et al. 2019). In the Mud Motor project, the dredged harbor sediments were partly deposited at the end of this channel, with the aim to reduce recirculation into the harbor and provide additional substrate for a lateral growth of the salt marsh ${ }^{1}$.

A small amount of freshwater is discharged through the port of Harlingen, less than $5 \mathrm{~m}^{3} \mathrm{~s}^{-1}$ in the annual mean. With an annual mean discharge of $200 \mathrm{~m}^{3} \mathrm{~s}^{-1}$, the Kornwerderzand sluice, which is located approximately $10 \mathrm{~km}$ further southwest (Fig. 1), forms one of the largest freshwater sources in the Dutch Wadden Sea (Duran-Matute et al. 2014; Schulz and Gerkema 2018). Here, water from the IJsselmeer is discharged into the Wadden Sea at low tide. Lateral density gradients in estuaries lead, in general, to a residual transport of sediment toward the freshwater

\footnotetext{
${ }^{1}$ For legal reasons, disposal at the new location is not always possible; see Baptist et al. (2019) for details.
} 


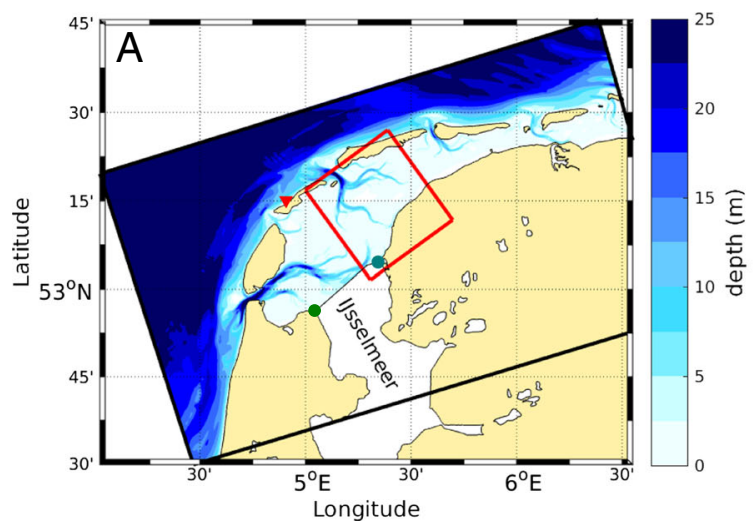

Fig. 1 Numerical model domain and bathymetry of $\mathbf{A}$ the larger setup (dws200), with boundaries of the nested domain indicated in red, and $\mathbf{B}$ enlargement of the nested setup domain (mm80), with a further enlargement of the Kimstergat channel. The dots in $\mathbf{A}$ indicate the position of the sluices in Den Oever (green) and Kornwerderzand (turquoise); the red triangle indicates the weather station on Vlieland.

source (Simpson et al. 1990; Jay and Musiak 1994). For the Kimstergat channel investigated in this study, the freshwater source is located in a way that freshwater is advected with the flood current, which causes a periodic salinity stratification inverse to the classical picture of estuarine circulation (Schulz and Gerkema 2018).

Westerly and especially southwesterly winds are prevailing in the study area (see Fig. 2A). This is in accordance with findings for wind patterns in the whole Dutch Wadden Sea (Reise et al. 2010; Keijsers et al. 2014; Gerkema and Duran-Matute 2017). Wind conditions in the modeled time

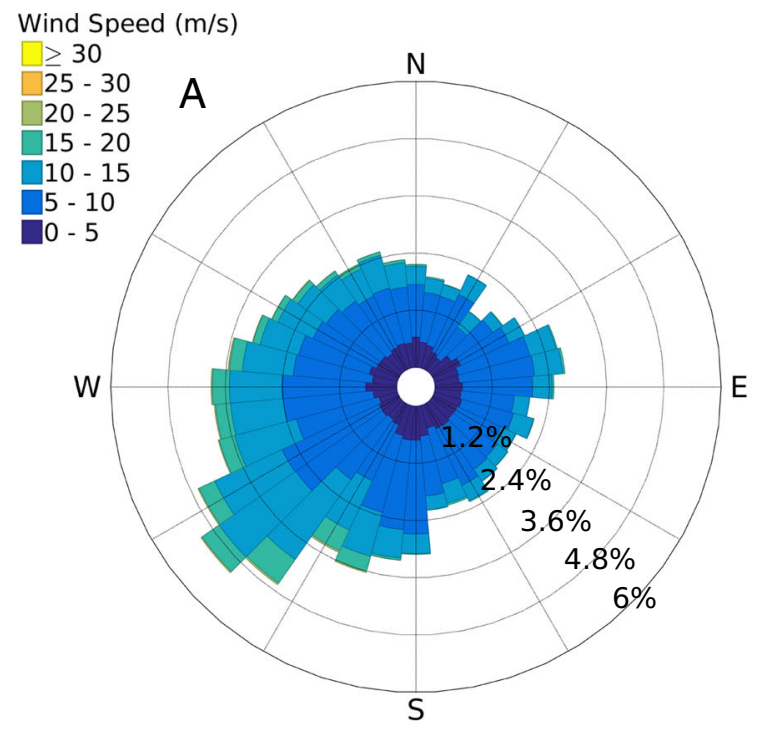

Fig. 2 Frequency distribution of wind direction and wind speed for (A) the years 2005 to (including) 2014 and (B) the year 2009. The wind direction indicates the direction from which the wind blows. Red dots in (B) indicate the wind scenarios chosen to investigate variable wind effects on suspended sediment transport. Wind data (at a resolution of period (year 2009, Fig. 2B) are fairly close to the long-term mean conditions.

\section{Methods}

\section{The Numerical Model}

Simulations are performed with the coastal ocean model GETM (General Estuarine Transport Model; Burchard and Bolding (2002)). GETM solves the 3D baroclinic, hydrostatic

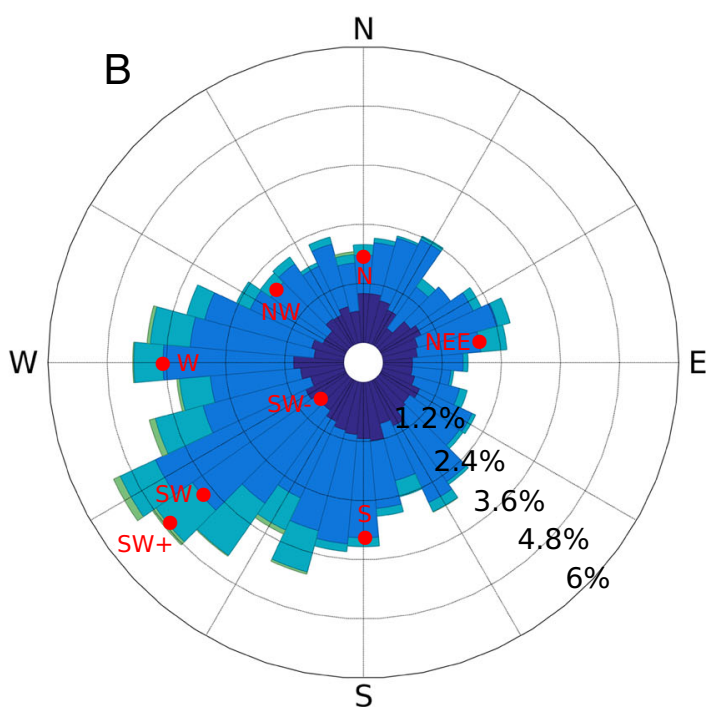

$10 \mathrm{~min}$ ) were taken from the Vlieland weather station of the Royal Netherlands Meteorological Institute (KNMI), which is close to the study area and lies exposed to wind from all directions (Gerkema and Duran-Matute 2017) 
Reynolds-Averaged Navier-Stokes equations and additional prognostic equations for temperature, salinity, and biogeochemical tracers (e.g., suspended particulate matter, SPM). Transport schemes in GETM exhibit low spurious mixing (Klingbeil et al. 2014). The turbulent vertical viscosity and diffusivity are calculated by the General Ocean Turbulence Model (GOTM; Burchard et al. (1999)). The present study applied a $k-\varepsilon$ model with the algebraic second moment closure of Canuto et al. (2001), Version A. For the prognostic equations of both quantities, flux boundary conditions are prescribed, based on the logarithmic law of the wall at the bottom and turbulence injection at the surface. With this, the estuarine circulation driven by the interplay of density gradients and dynamic turbulent boundary layers is accurately captured (see, e.g., Purkiani et al. (2016), Nasermoaddeli et al. (2018)). In addition, the drying and flooding of intertidal flats are realistically accounted for (see sec. 5.2 in Klingbeil et al. (2018)). For the governing equations and more details of GETM and GOTM, the interested reader is referred to the review papers by Klingbeil et al. (2018) and Umlauf and Burchard (2005).

A simple SPM model, already used in Sassi et al. (2015) and Schulz and Gerkema (2018), was coupled to GETM via FABM (Framework for Aquatic Biogeochemical Models; see Bruggeman and Bolding (2014)). In our setup, a single class of sediment is used, characterized by a constant settling velocity $w_{s}$, an erosion constant $\alpha_{e}$, and a critical resuspension threshold $\tau_{c}$.

Sediment is eroded when the bottom shear stress $\tau_{b}$, calculated under the assumption of the logarithmic law of the wall in terms of the near-bed velocities and a roughness length, exceeds the critical threshold. The erosion flux is calculated via:

$F_{e}=\alpha_{e} \max \left\{\left(\frac{\left|\tau_{b}\right|}{\tau_{c}}-1\right)^{1.5}, 0\right\}$

(see Sassi et al. (2015), Schulz and Gerkema (2018)).

A grain size analysis performed for sediment samples taken at the respective simulated disposal locations showed that the top $10 \mathrm{~cm}$ of sediment are rather homogeneous in the investigated area, except for the position at the end of the Kimstergat channel, where a thin $(1.5 \mathrm{~cm})$ layer of fine grained sediment mixed with shredded shells was present on top of an impenetrable clay layer. This means that a more advanced erosion model, e.g., a two-layered bed model to account for the buffering of fines in a sandy seabed as described in Van Kessel et al. (2011), is not needed for the model application in this study.

The use of a cohesive sediment model was omitted, as bottom sediment samples obtained from the new disposal location suggest that the deposited fine-grained sediments from the port are not cohesive. In consequence, also the use of a sediment model with variable settling velocity, to account for flocculation processes, was omitted.

\section{Model Setup}

To accurately resolve the dynamics in the narrow Kimstergat channel, a small model domain with a horizontal resolution of $80 \mathrm{~m}$ (hereafter referred to as $\mathrm{mm} 80$, for Mud Motor) is nested into a larger domain covering the whole Dutch Wadden Sea with 200m spatial resolution (hereafter referred to as dws200). The dws200 setup has already been extensively described in Duran-Matute et al. (2014), and consequently only a brief summary will be given here: As shown in Fig. 1A, the rectangular dws200 domain is rotated $17^{\circ}$ anticlockwise with respect to the east-west axis and covers the area between the corner points $\left(4.4693^{\circ}\right.$ $\left.\mathrm{E}, 52.4975^{\circ} \mathrm{N}\right) ;\left(4.0260^{\circ} \mathrm{E}, 53.3269^{\circ} \mathrm{N}\right) ;\left(6.3871^{\circ} \mathrm{E}\right.$, $\left.53.7607^{\circ} \mathrm{N}\right) ;\left(6.7896^{\circ} \mathrm{E}, 52.9232^{\circ} \mathrm{N}\right)$. Calculations were carried out on an equidistant grid with 200-m spatial resolution and 30 vertical sigma layers, using a 3D timestep of $40 \mathrm{~s}$ and 10 2D subcycles per 3D timestep.

Bathymetric data is generated using the "vaklodingen" data set, which is a freely available bathymetric data set with a $20 \mathrm{~m}$ spatial resolution produced in a survey program carried out by Rijkswaterstaat (a Dutch governmental organization) (Wiegman et al. 2005). Details on the construction of the bathymetry for dws200 can also be found in DuranMatute et al. (2014), and the finer bathymetry for mm80 was generated the same way. Meteorologic forcing (with a temporal and spatial resolution of $3 \mathrm{~h}$ and $1 / 16^{\circ}$ ) for both model setups was obtained from the German Weather Service (DWD). Lateral boundary conditions for the dws 200 setup were obtained from a two-dimensional model with data assimilation operated by Rijkswaterstaat, and threedimensional boundary conditions (temperature, salinity) were provided by a GETM North Sea model (again, see Duran-Matute et al. (2014), Gräwe et al. (2016) for details). Model results of the dws200 setup were validated in DuranMatute et al. (2014) and show an excellent agreement with observational data sets.

The domain of the mm80 setup is shown in Fig. 1B. It is rotated $45^{\circ}$ with respect to the west-east axis, and the corners of the domain are located at $\left(5.3081^{\circ} \mathrm{E}, 53.0265^{\circ}\right.$ $\mathrm{N})$; $\left(4.9996^{\circ} \mathrm{E}, 23.2800^{\circ} \mathrm{N}\right) ;\left(5.6971^{\circ} \mathrm{E}, 53.1959^{\circ} \mathrm{N}\right)$; $\left(5.3896^{\circ} \mathrm{E}, 53.4505^{\circ} \mathrm{N}\right)$. The area is covered by $403 \times 438$ computational points in the $x$ ("parallel to the coast") and $y$-direction, respectively, and again 30 vertical sigma layers. Calculations were carried out using a 3D and 2D timestep of $18 \mathrm{~s}$ and $1.8 \mathrm{~s}$, respectively. Boundary conditions (on the southwestern and northeastern bound of the domain and between the islands) are taken from the dws 200 model 
results, at a temporal resolution of $10 \mathrm{~min}$ for the twodimensional variables (surface elevation, depth-averaged velocity) and $30 \mathrm{~min}$ for the three-dimensional variables (salinity, temperature). The commonly used Flather boundary condition (Flather and Davies 1976) is applied: Prescribed barotropic transports and surface elevations from the outer model (dws200) are used to nudge to the modelled internal quantities. The 3D normal velocity profile at the open boundaries is calculated via the momentum equation depending on the normal density gradient in terms of the prescribed boundary data for salinity and temperature.

Parameters for the sediment model were inferred from observational data on suspended sediment transport in (Schulz and Gerkema 2018), by comparing results from a water column model (the same as that used in this study) to observational data. By varying the input parameter for the sediment model over a wide realistic range, an optimal set of parameters could be identified: A settling velocity of $w_{s}=1 \times 10^{-3} \mathrm{~m} \mathrm{~s}^{-1}$, a critical erosion threshold of $\tau_{c}=0.25 \mathrm{~kg} \mathrm{~m}^{-1} \mathrm{~s}^{-2}$, and an erosion constant of $\alpha_{e}=$ $1.2 \times 10^{-5} \mathrm{~kg} \mathrm{~s}^{-1} \mathrm{~m}^{-2}$ were found to best reproduce the fine sediment dynamics in the investigated Kimstergat channel, and are therefore also used in this study. Additional details can be found in Schulz and Gerkema (2018).

\section{Modeling Strategy}

A continuous hydrodynamics-only (no sediment model) run was started in November 2008 and after a 2-month spinup period, model data from 2009 (a year during which wind conditions were close to the long-term mean) are analyzed and used as hotstart data for independent scenario simulations with sediment. A set of typical wind climates for the study area was chosen, marked by the red dots in Fig. 2B. Corresponding episodes of approximately 3 days (6 tidal cycles), during which the wind direction is stable and the wind speed is in the right order of magnitude, were identified in the meteorological data for 2009, and are summarized in Table 1. The time period of 3 days was chosen for two reasons: Firstly, the wind direction in the study area is mostly not stable for times longer than 3 days, and secondly, decisions on the disposal of dredged sediment can only take into account meteorological forecasts, which are less accurate for predictions further into the future.

To examine the dependence of suspended sediment transport on the wind speed, three scenarios of southwesterly winds with different strengths are chosen (from weak to strong: "SW-," "SW," and "SW+"). To cover the dependence of sediment transport on wind direction, periods of time with an average wind speed of approximately $10 \mathrm{~m} \mathrm{~s}^{-1}$ were identified for southerly ("S"), westerly ("W"), and northerly ("N") winds. Instead of easterly winds, we chose a period with winds from the north-east-east ("NEE"), as persistent wind from this direction occurs more often than wind from straight east (see Fig. 2). To account for the prevailing westerly winds, this set of scenarios is completed with an event of northwesterly winds ("NW").

With these scenarios, the impact of different wind directions, wind speeds, and spring/neap tide on the sediment transport will be investigated. Each scenario (see Table 1) starts with three bottom pools of sediment, one close to the harbor of Harlingen, and two in the middle and at the end of the Kimstergat channel, respectively. The sediment in each pool is treated independently in the model. Each respective bottom pool initially consists of a concentration of $1.25 \mathrm{~kg} \mathrm{~m}^{-2}$ equally spread over an area of $400 \times 400 \mathrm{~m}$, which equals 200 tons of sediment. Each 200 tons bottom pool is approximately equal to the amount of sediment in one dumping load of the dredging ship Adelaar: The Adelaar carries a fine-grained mud-water mixture with a wet weight of $1230 \mathrm{~kg} \mathrm{~m}^{-3}$ (M. Baptist, pers. comm.). According to Flemming and Delafontaine (2000) and Flemming and Delafontaine (2016), this wet weight corresponds to a dry sediment weight of approximately $370 \mathrm{~kg} \mathrm{~m}^{-3}$. One load of the Adelaar (carrying capacity, $600 \mathrm{~m}^{3}$ ) contains therefore 223 tons of (dry) sediment.
Table 1 Set of different wind climates in 2009, typical for the western DWS. The wind direction denotes the direction from which the wind is blowing, with $90=$ east, $180=$ south, $270=$ west, and $360=$ north. Start times were set to slack tide before ebb (20 min after HW in Harlingen); each time interval covers 6 tidal periods after start. Scenario "W" was during spring tide; "W2" during neap tide conditions.

\begin{tabular}{lllll}
\hline Scenario & Start time (UTC) & $\begin{array}{l}\text { Avg. wind } \\
\text { direction }(\mathrm{deg})\end{array}$ & $\begin{array}{l}\text { Avg. wind } \\
\text { speed }\left(\mathrm{ms}^{-1}\right)\end{array}$ & $\begin{array}{l}\text { Max. wind } \\
\text { speed }\left(\mathrm{ms}^{-1}\right)\end{array}$ \\
\hline SW- & $11 / 07 / 200922: 50$ & 213 & 5.5 & 10 \\
SW & $06 / 05 / 200918: 40$ & 225 & 9.8 & 16 \\
SW+ & $24 / 11 / 200912: 00$ & 228 & 14.1 & 19 \\
W & $07 / 07 / 200909: 00$ & 282 & 11.3 & 18 \\
W2 & $03 / 05 / 200915: 30$ & 264 & 10.0 & 15 \\
NW & $30 / 09 / 200905: 30$ & 286 & 9.9 & 17 \\
N & $02 / 06 / 200903: 50$ & 338 & 9.4 & 12 \\
NEE & $11 / 05 / 200922: 40$ & 73 & 10.4 & 14 \\
S & $12 / 11 / 200904: 10$ & 189 & 9.2 & 20 \\
\hline
\end{tabular}




\section{Model Validation}

As already mentioned above, the results from the dws 200 model setup show excellent agreement with observational data sets of sea surface height ( $\mathrm{SSH}$ ), salinity, and temperature (Duran-Matute et al. 2014; Sassi et al. 2016).

To check the accuracy of the nested mm80 setup, the modeled SSH is compared with data from the tide gauge in Harlingen (located at $53^{\circ} 10.602 \mathrm{~N}, 5^{\circ} 24.588 \mathrm{E}$, data available at a temporal resolution of $10 \mathrm{~min}$ ). As the modeled SSH can technically not fall below the water depth of the respective computational grid point, model results from the grid point located at $53^{\circ} 10.680 \mathrm{~N}, 5^{\circ} 24.516 \mathrm{E}$, $160 \mathrm{~m}$ away from the location of the tide gauge, were used for the comparison. The water depth at that point $(1.53 \mathrm{~m})$ is deeper than at computational points closer to the tide gauge, and the modeled SSH falls below its minimum value in less than $4 \%$ of the modeled time period (these few data points were excluded from the comparison). For the year 2009, the calculated coefficient of determination for the modeled and observed SSH is $R^{2}=0.98$, and the root-mean-square (rms) error is $\epsilon_{r m s}=0.09 \mathrm{~m}$ (see Fig. 3B). By means of example, the observed and modeled SSH for the first two weeks of the modeling period are displayed in Fig. 3A.

To further check the performance of the model, model results from one station close to the harbor of Harlingen, at the deeper end of the investigated Kimstergat channel $\left(53.182^{\circ} \mathrm{N}, 5.4102^{\circ} \mathrm{E}, 6.46 \mathrm{~m}\right.$ water depth, hereafter referred to as station 1), and data from the shallow end of the channel $\left(53.2279^{\circ} \mathrm{N}, 5.45810^{\circ} \mathrm{E}\right.$, water depth $3.52 \mathrm{~m}$, station 2) are analyzed. These positions correspond to the old (station 1) and new (station 2) dumping locations in the channel and are indicated in Fig. 1B. Ship-based measurements have been carried out in the vicinity of both stations in 2015-2017 (details on the data acquisition and results can be found in Schulz and Gerkema (2018)). Even though observational and modeled data cannot be directly compared (as they refer to different years), the identification of common characteristics in both data sets is possible.

The main flow direction of the tidal current is along the channel, with flood current (indicated in Fig. 1B) pointing toward the northeast, where the channel approaches a watershed, and ebb current going toward the harbor of Harlingen.

Although the length of one tidal cycle (i.e., the time between two consecutive slack tides before ebb) is rather variable, the tidal current exhibits a systematic asymmetry between ebb and flood phase near station 1. On average, the ebb phase lasts $7.4 \mathrm{~h}$, with a maximal current velocity of $0.45 \mathrm{~ms}^{-1}$. The flood phase is shorter, but the maximal current velocity is nearly twice as fast $\left(0.82 \mathrm{~ms}^{-1}\right)$. At the end of the Kimstergat channel (station 2), the average current velocities are approximately $20 \%$ smaller, but the tidal flow exhibits the same asymmetry. These asymmetries, both in the length of the ebb and flood phase and in absolute current velocity are also visible in the observational data Schulz and Gerkema (2018). Over the spring and neap cycle, the tidal current magnitude deviates by up to $40 \%$ from the average tidal current.

A characteristic periodic stratification, inverse to the situation in classical estuaries (see "Introduction" and Schulz and Gerkema (2018)), is visible in the modeled data: An initial salinity stratification diminishes when water from the shallow water shed enters the Kimstergat channel with the ebb current, and is eventually destroyed within the first half of the ebb phase. After the tide has turned to flood, the salinity stratification is rapidly established again, but disappears shortly after. This is caused by freshwater advection from a different source, the port of Harlingen. After this intermediate peak, salinity stratification increases gradually with the flood current, when freshwater from the Kornwerderzand sluice is transported toward station 1. At station 2, the periodic salinity stratification is still visible, but considerably smaller. This very characteristic periodic salinity stratification has also been found in the observational data sets, and
Fig. 3 A Observed (black line) and modelled (red line) SSH at the tide gauge of Harlingen. B Observed vs. modeled SSH for the year 2009, at a temporal resolution of 15 minutes
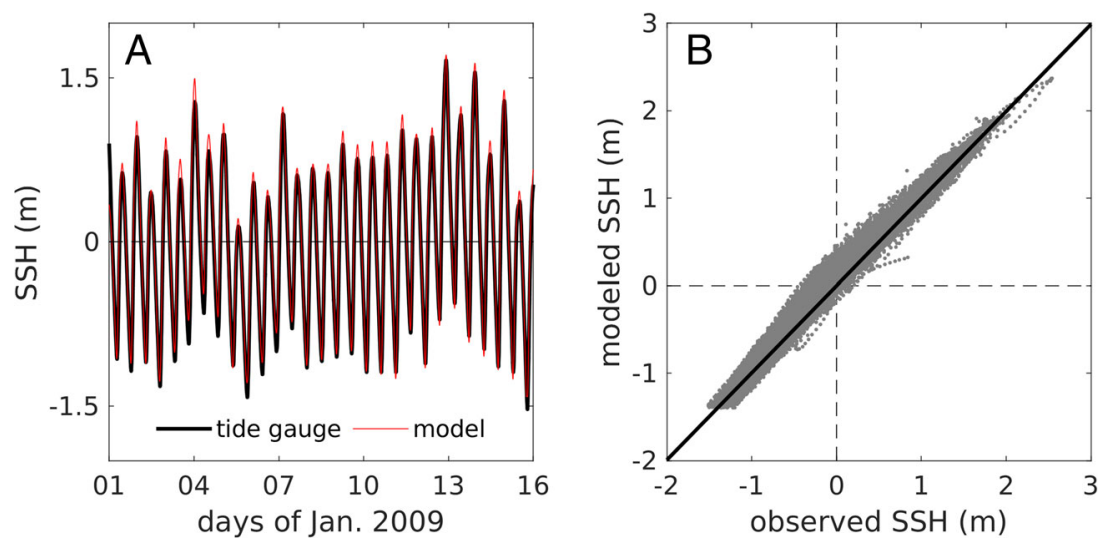
the observed top to bottom salinity differences are well in line with the model results.

The validation indicates that the hydrodynamical drivers of sediment transport are well captured by the model used in this study.

The evaluation of the performance of the sediment model, on the other hand, is less straightforward. The idealized character of the study, with the only sediment sources being the simulated initial disposals, neglects background sediment concentrations, and the simulated transport rates are therefore not directly comparable with observed ones. However, a number of similarities between observed and modeled (see "Results") sediment transport characteristics found in the study area indicate that the model results can be trusted regarding the aim of this study. Measurements, which were only performed during low wind speeds, confirm that sediment in the Kimstergat is generally transported in flood direction, away from the harbor of Harlingen and toward the water shed. Also, the offshore transport component found for sediment dumped in the middle of the channel is in line with observations from this position (Schulz and Gerkema 2018).

\section{Classification of the Model Results}

To allow for a quantitative assessment and the comparison of the modeled sediment dispersal under different conditions, target areas are defined and displayed in Fig. 4. Area 1 (indicated in green in Fig. 4) comprises the intertidal mudflat (at depths smaller than $1 \mathrm{~m}$ below NAP) in front of the salt marsh, northeast of the Kimstergat channel. As sediment in this area has the potential to be transported toward the near-coastal salt marsh, sediment deposition here is considered to be a positive outcome when assessing the

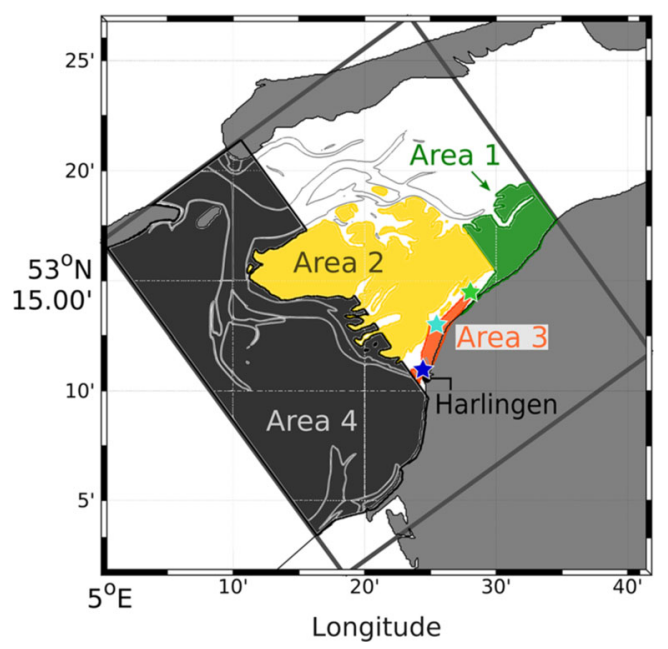

Fig. 4 Study area with areas 1-4 and initial dumping positions (stars) indicated. In gray, the 5-m isobath is plotted for better orientation functioning of the Mud Motor. Area 2 (yellow in Fig. 4) covers the intertidal flats (again depths shallower than $1 \mathrm{~m}$ below NAP) between the two branches of the channel connected to the tidal inlet between Vlieland and Terschelling. This region is connected to area 1 , but sediment deposited here is less likely to be transported onto the salt marshes. The Kimstergat channel (deeper than 2 m below NAP), including the area in front of the Harlingen harbor and the three sediment dumping positions, is defined as area 3 (orange in Fig. 4). Sediment in this area is still mobile and can potentially be transported toward the marshes or recirculated into the port. Area 4 marks everything west of the harbor of Harlingen (black in Fig. 4). A fifth important criterion to assess the success or failure of sediment nourishment under different conditions is the amount of sediment that is exported from the model domain over the tidal divide in the northeast. The locations of the initial sediment pools are also indicated in Fig. 4. In the following, blue colors will always refer to sediment dumped near the port of Harlingen, turqouise to sediment from the middle of the Kimstergat channel, and green to sediment originating from the end of the channel.

\section{Results}

In the following "Sediment Transport at Low Wind Speed", the analysis of sediment transport is explained in detail for the scenario "SW-," representing the prevailing wind conditions in the study area. The impact of wind speed, spring-neap cycle, and wind direction is analyzed in "Response to Higher Wind Speeds and the Effect of the Spring-Neap Cycle" and "Response to Wind Direction". Freshwater effects are analyzed and discussed in Appendix A.

\section{Sediment Transport at Low Wind Speed}

The scenario "SW-", a time period with prevailing weak southwesterly winds, represents a phase of calm conditions in the study area, and will serve as a reference scenario to investigate the transport of dumped sediment at low wind speeds.

As visible in Fig. 5A, the sediment is very mobile during the first three tidal cycles after the disposal. Local resuspension is stronger during flood phases, when the absolute current velocities are higher. After the fourth tidal cycle ( $50 \mathrm{~h}$ after the sediment pools were initiated), over $80 \%$ of the sediment is not resuspended anymore, implying that this fraction is now deposited at a permanent position (for the present wind conditions).

In Fig. 5B, the extent and spatial distribution of the deposited sediment after $50 \mathrm{~h}$ is displayed. Virtually no 


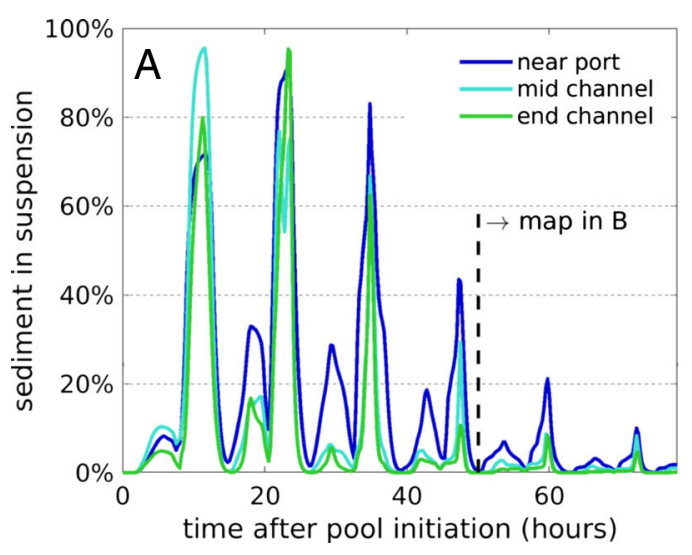

Fig. 5 A The fraction of sediment in suspension for sediment pools initiated near the port of Harlingen (old dumping position, blue), in the middle of the Kimstergat channel (turqouise), and at the end of the Kimstergat (new dumping position for the mud motor, green); dashed line indicates the point in time for which the map in $\mathbf{B}$ is provided.

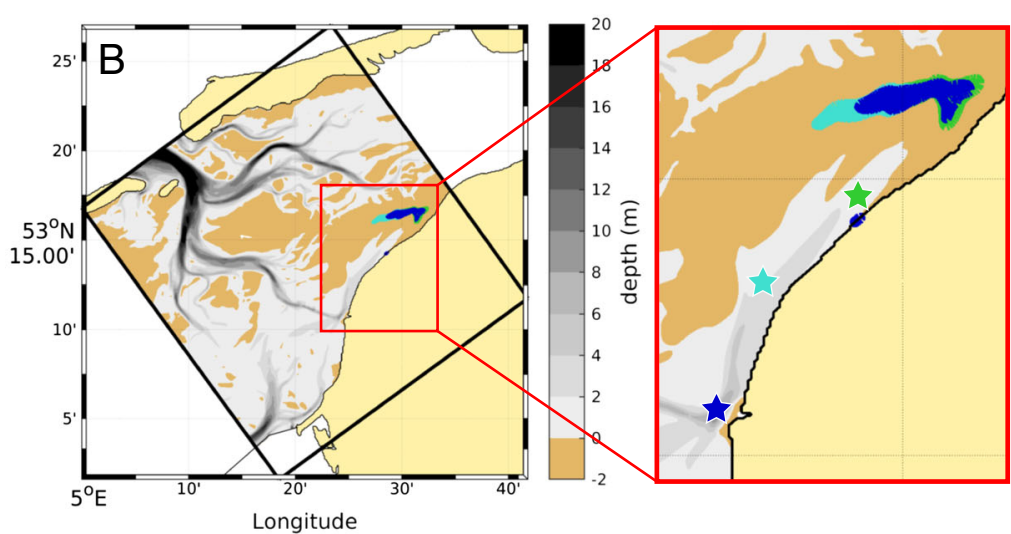

B The spatial distribution of sediment (bed plus water column) after $50 \mathrm{~h}$ (same colors, 10 contour lines equally spaced from concentrations of $0-0.25 \mathrm{~kg} \mathrm{~m}^{-2}$ each). The bathymetric color map was changed to grayscale here for a better visibility. Stars indicate again the initial positions of the respective sediment pools sediment is exported from the model domain, and sediment originating from each dumping position is spread over only a relatively small area. Over $90 \%$ of the sediment dumped either near Harlingen or at the end of the Kimstergat channel is deposited in area 1, with the potential to contribute to the desired salt marsh growth. Sediment originating from the end of the channel reaches area 1 approximately $10 \mathrm{~h}$ earlier than sediment deposited near the port, and is deposited slightly closer to the coastline, but the qualitative difference between the dumping at either of the two positions is rather small. Sediment dumped in the middle of the tidal channel is partly transported further offshore, only $70 \%$ is deposited in area 1 ; the remaining $30 \%$ in area 2 . These results suggest that a disposal of dredged sediment far away from the port, at the end of the channel, is not necessary for marsh nourishment under calm conditions.

\section{Response to Higher Wind Speeds and the Effect of the Spring-Neap Cycle}

In the presence of weak winds from the southwest, most of the dumped sediment is deposited in area 1 (see "Sediment Transport at Low Wind Speed" above). Stronger winds from the same direction generally result in an export of sediment over the northeastern Terschelling watershed.

In Fig. 6A, the amount of sediment in the Kimstergat channel (including the dumping locations) and the amount of sediment exported over the watershed in the presence of intermediate southwesterly winds are displayed. After the first two tidal periods (three for dumping near the port, blue line), nearly all of the initial sediment is eroded and transported out of the Kimstergat channel. Export over the watershed starts approximately $35-40 \mathrm{~h}$ after the initialization of the sediment pool, regardless of the dumping position. After 5 tidal cycles, over $90 \%$ of the initial sediment has left the model domain.

Scenario SW (displayed in Fig. 6A) was some days before spring tide conditions. Scenario SW+ (Fig. 6B, in the presence of stronger winds from the same direction) was during full neap conditions. The reduced maximal current speeds have a strong diminishing effect on the local resuspension of sediment, especially for sediment deposited near the port, at relatively deep waters. Resuspension of the initial sediment pool and the export of sediment from the channel is slower than during spring tide or average conditions, but sediment that has once left the Kimstergat channel is transported over the watershed rapidly, within
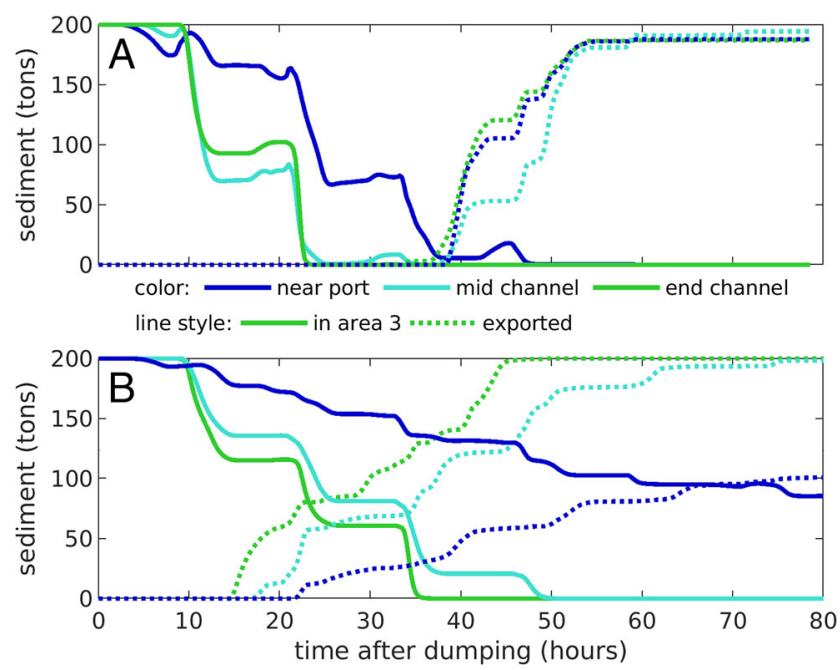

Fig. 6 Sediment in area 3 (solid lines) and cumulative fraction of sediment that is exported over the tidal divide in the northeast (dotted lines) for A scenario "SW," and B scenario "SW+." Initial dumping positions are color coded 
the following tidal cycle, due to the strong wind. Strong southwesterly winds during spring tide conditions are likely to result in an even faster export (within 3-4 tidal cycles) of the initial sediment pool over the tidal divide, independent of the exact dumping position within the Kimstergat channel.

To further analyze the interplay of spring-neap tide and wind forcing on the sediment transport patterns, this time for westerly winds, the scenarios "W" (full spring tide) and "W2" (full neap tide) are compared:

During spring tide conditions, a large fraction of sediment is transported out of the Kimstergat channel and onto the intertidal area 1 within the first two tidal cycles. Even though the transport for sediment originating from near the port is slower, this sediment eventually accumulates in area 1, too. Export over the watershed only occurs when the wind speed increases (to over $10 \mathrm{~m} \mathrm{~s}^{-1}$ after approximately $65 \mathrm{~h}$ in this scenario). Before that, the comparably lower wind speeds allowed sediment to be deposited in the intertidal area. Neap tide conditions (scenario "W2") cause reduced local resuspension rates and therefore a longer residence time of deposited material in the channel. However, the general transport patterns are similar to the spring tide conditions: Sediment is settling in the intertidal area, and is exported only at relatively high wind speeds of over $10-15 \mathrm{~m} \mathrm{~s}^{-1}$.

For the functioning of the Mud Motor, these model results suggest that spring tide accelerates the transport of sediment out of the Kimstergat channel, while neap tide conditions decelerate this transport. The export of sediment that has already accumulated on the mudflat is, however, determined by the wind speed rather than by the spring/neap cycle.

\section{Response to Wind Direction}

After analyzing the sediment transport characteristics during westerly wind conditions in the above section, the transport patterns in the presence of winds from the NW, N, NEE, and $\mathrm{S}$ will be the focus of the following section. For a better overview, a selection of sediment transport characteristics for each investigated wind direction is summarized in Table 2, namely: The fraction of initially disposed sediment that is present on the mudflat (area 1, marked green in Fig. 4) after 50 h (4 tidal cycles) for each dumping position; the maximum share of sediment that is (intermittently) transported to the southwest beyond the port of Harlingen (area 4, black in Fig. 4), again for each respective dumping position; And additional details on the possible export of sediment over the shallow watershed in the northeast.

\section{Northwesterly and Southerly winds}

Although Table 2 provides a good overview of some key values when assessing the functioning of the Mud Motor, it has to be kept in mind that these numbers alone cannot reflect the different processes that affect sediment transport.
Table 2 Numbers refer to fraction of the initial sediment pool (200 tons). In each cell of the second and third columns, the first number refers to sediment initially dumped near Harlingen, second number to sediment dumped mid channel, and the last number to sediment from the end of the channel. Numbers in the third column refer to the maximum amount of sediment that was (intermittently) transported into area 4 during the modeled scenario..

*determined from scenarios "SW" and "SW+".

\begin{tabular}{llll}
\hline Scenario & $\begin{array}{l}\text { In area 1 } \\
\text { (after 50 h) }\end{array}$ & $\begin{array}{l}\text { In area } 4 \\
\text { (max.) }\end{array}$ & $\begin{array}{l}\text { Export over } \\
\text { watershed }\end{array}$ \\
\hline SW- & $93 \%$ & $10 \%$ & $\begin{array}{l}\text { Rapidly } \\
\text { for wind }\end{array}$ \\
& $70 \%$ & $8 \%$ & $\gtrsim 5 \mathrm{~ms}^{-1 *}$ \\
& $100 \%$ & - & Rapidly \\
$\mathrm{W} / \mathrm{W} 2$ & $9 / 17 \%$ & for wind \\
(spring / neap) & $93 / 62 \%$ & $5 / 10 \%$ & $\approx 10 \mathrm{~ms}^{-1}$ \\
& $97 / 84 \%$ & - & \\
$\mathrm{NW}$ & $100 / 81 \%$ & $30 \%$ & No \\
& $25 \%$ & $15 \%$ & \\
& $60 \%$ & $1 \%$ & No \\
$\mathrm{N}$ & $94 \%$ & $43 \%$ & \\
& $6 \%$ & $63 \%$ & No \\
& $5 \%$ & $13 \%$ & \\
$\mathrm{NEE}$ & $41 \%$ & $40 \%$ & Slowly \\
& $7 \%$ & $55 \%$ & after \\
& $5 \%$ & $13 \%$ & $40 \mathrm{~h}$ \\
\hline
\end{tabular}


Judging alone from the data in Table 2, the effect of wind from north-westerly wind directions (scenario "NW") on sediment transport seems to be comparable with the effect of southerly ("S") wind directions, but a detailed examination of the model results reveals considerable differences in the transport patterns between both scenarios: As visible in Fig. 7A, northwesterly winds trigger the successive accumulation of sediment in area 1, while sediment once brought to the intertidal flat in the presence of southerly winds (Fig. 7B) does not necessarily stay there, but is transported back and forth with the tide and partly exported over the watershed.

With concurrent northwesterly winds, sediment initially deposited at the end of the Kimstergat channel arrives faster on the mudflat than sediment from the middle of the channel or from near the port. Before the wind direction changes (dashed line, $65 \mathrm{~h}$ after pool initiation), a total fraction of over $60 \%$ (sediment from near the port) to $99 \%$ (sediment from the end of the channel) of the initially dumped sediment have accumulated in the intertidal area. Compared with the reference scenario at low wind speed ("SW-", see "Sediment Transport at Low Wind Speed"), sediment accumulates closer to the coastline, which is beneficial for the aim of the Mud Motor. During southerly winds, sediment originating from the middle of the channel (turquoise lines) passes area 2 before being transported towards the mudflat close to the salt marsh. In general, sediment remains comparably mobile under southerly wind conditions; large amounts are frequently exchanged mainly between the channel, the mudflat, and the remaining northeastern part of the domain. Compared with the rapid export of sediment over the watershed that occurs during southwesterly wind conditions (scenarios SW and SW+), export in the presence of southerly winds in hindered.
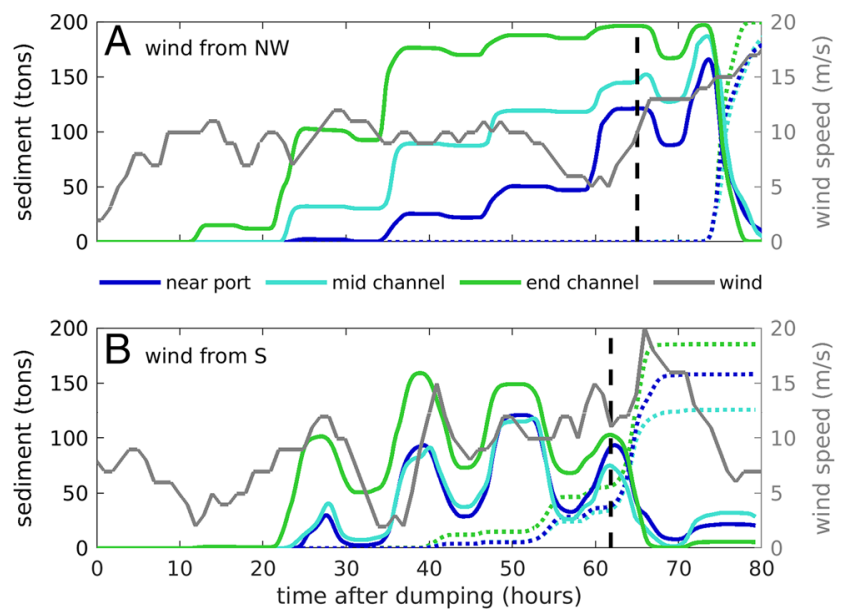

Fig. 7 Accumulation of sediment in area 1 (solid lines, initial dumping position color coded) and the respective cumulative export over the watershed (dotted lines, again color coded) for scenario A NW and $\mathbf{B}$ $\mathrm{S}$. Wind speed is indicated in gray. The vertical dashed line indicates a change in wind direction from $\mathbf{A}$ NW to SW and $\mathbf{B}$ S to W
Toward the end of both simulated phases, a change in wind direction and a simultaneous increase in wind speed lead to the sudden export of sediment accumulated on the mudflat over the watershed (Fig. 7A,B).

\section{Northerly and Easterly Winds}

While winds from the northwest and south lead to very different sediment transport patterns, northerly and easterly winds have a similar effect on the sediment dynamics in the study area. In the presence of wind from both directions, sediment transport from the channel toward the tidal divide is counteracted. No sediment is exported from the model domain, but the accumulation of sediment on the intertidal flat is hindered (compared with scenarios "NW" and "SW"). Most of the initially dumped sediment stays very mobile throughout the simulated period, and a lot of recirculation from the flats into the Kimstergat channel occurs.

A considerable fraction of sediment (occasionally up to over $50 \%$, highest values for sediment deposited near the port and in the middle of the Kimstergat) is intermittently transported toward the southwest, to area 4 beyond the harbor of Harlingen. Even though sediment originating from any of the initial dumping positions is eventually transported toward the intertidal flat (area 1), recirculation into the channel takes place throughout the whole simulated period. This increases the amount of available mobile sediment, and therefore the chances for recirculation into the harbor of Harlingen.

In the presence of winds from northerly directions, sediment transport is very sensitive to the initial dumping position. In Fig. 8, the spatial distribution of sediment from the three dumping locations, $50 \mathrm{~h}$ after the start of scenario $\mathrm{N}$ (at slack tide), is displayed. While sediment from the end of the channel was transported toward the northeastern mudflat, sediment from the the other positions is spread over the whole Kimstergat channel, and even beyond the port of Harlingen. Regarding the aim of the Mud Motor, these results suggest that the shift of the sediment disposal location from near the port toward the new position at the end of the Kimstergat really is important in the presence of northerly winds.

\section{Discussion}

\section{Model Limitations}

\section{Wind Waves}

The Dutch Wadden Sea is effectively sheltered from incoming waves from the North Sea by barrier islands. These islands also limit the fetch for the generation 
Fig. 8 Same as Fig. 5B, for scenario $\mathrm{N}$

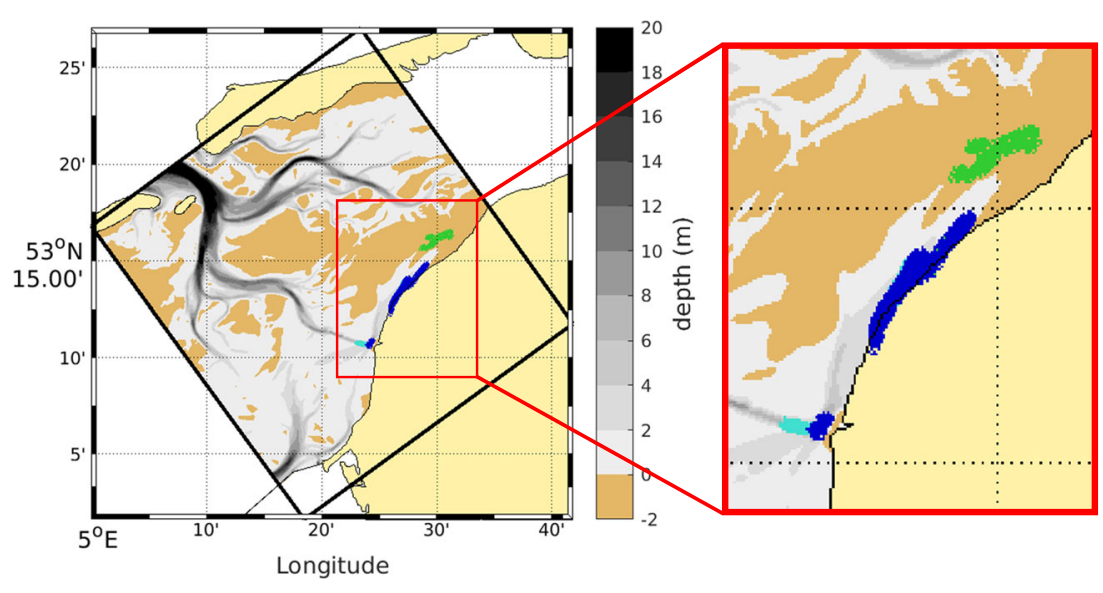

of locally produced waves. Hence, wind waves are not considered in the applied model.

The importance of wind waves in a coupled model system was investigated in a part of the Wadden Sea very similar to our study side (Lettmann et al. 2009). The authors state that at small wind speeds $\left(<7.5 \mathrm{~m} \mathrm{~s}^{-1}\right)$, waves are negligible in the Wadden Sea system. At moderate wind speeds $\left(<13 \mathrm{~m} \mathrm{~s}^{-1}\right.$, the presented study is focused on typical wind speeds of $10 \mathrm{~m} \mathrm{~s}^{-1}$ ), wind waves erode sediment in front of the barrier islands and cause enhanced sediment import, but sediment import into the Wadden Sea is not considered in the presented study. At wind speeds greater than $13 \mathrm{~m} \mathrm{~s}^{-1}$, waves can cause enhanced erosion on the tidal flats. The already rapid erosion on the tidal flat observed during scenario "SW+" (the only scenario with wind speeds higher than $13 \mathrm{~m} \mathrm{~s}^{-1}$ ) might therefore still be underestimated by the model. Storm events and large waves, however, are not the main focus of this study, as the operation of the dredging ship and hence active sediment disposal is limited to relatively calm conditions. Another study, which investigates the importance of individual driving processes for sediment transport in different parts of the Wadden Sea, states that small-amplitude waves are ineffective for transport in subtidal channels, like the one investigated in this study (Gatto et al. 2017).

\section{Tidal Flats and Salt Marshes}

On the mudflat in front of the salt marsh, sediment transport, deposition, and erosion are also affected by waves during strong winds; biological processes like algae cover and the secretion of extracellular polymeric substances by benthic organisms (Tolhurst et al. 2002; Schindler et al. 2015), and sediment compaction and drainage during periods of emersion. These processes and their interplay are complex and beyond the scope of the model applied in this study. The calculated transports on the mudflat therefore have to be treated with care.
An extensive observational data set to investigate sediment transport on the mudflat was obtained in the context of the Mud Motor project, and is subject to another publication. However, results obtained from this data set are well in line with the modeled results presented in this study: The current regime on the mudflat was found to be generally flood dominant with a high dependency on wind speed. Winds from the southwest can reverse the ebb flow so that the current is directed in flood direction throughout the whole tidal cycle. This supports the model findings of sediment export over the watershed during these wind conditions. Winds from the northeast, on the other hand, can induce a net flux from the mudflat toward the channel, which could increase the chances for recirculation into the harbor (I. Colosimo, pers. comm., Colosimo et al. (2017)). These consistent results give confidence in the applied model. At high wind speeds (like in scenario "SW+"), the modeled rapid erosion on the tidal flat might still be underestimated.

The lateral growth of the salt marsh is to a large extent determined by the colonization of a mud flat area by salt marsh pioneer plants, which happens on longer (annual) time scales, and is not fully understood yet. Processes on the salt marsh are therefore not included in the presented model study, that is focused on short time scales, but are investigated elsewhere within the Mud Motor project (e.g., Regteren et al. (2017)).

\section{Sediment Model}

Initiating the sediment with a bottom pool is somewhat unrealistic, as the dredging ship discharges the loaded sediment at the water surface, but due to the shallow water depth (less than $10 \mathrm{~m}$ at all disposal locations) sediment would settle rather quickly during slack tide. As the transport processes during the simulated scenarios can only be compared when the sediment is initiated at the same time in the tidal cycle, this simplification is necessary. It has to be kept in mind, however, that a disposal of 
sediment during flood (ebb) tide will accelerate (decelerate) the transport of sediment in the direction of the mud flat.

As the harbor sediments were found to be highly noncohesive, a constant settling velocity is assumed in the model, which should reproduce the SPM sinking behavior sufficiently well. We cannot exclude, however, that the interaction of the deposited fine-grained sediment interacts with the locally occurring sediment to form flocs that exhibit a more dynamic settling behavior (Manning et al. 2010). The inclusion of this process in a model is challenging and requires detailed knowledge of the site-specific sediment characteristics (Manning et al. 2011), which exceeds what we can derive from the available observational data. We can only speculate that flocculation processes, and hence dynamic sinking velocities, can have a sorting effect, as slowly sinking material remains in the water column for a relatively long time, compared with quickly sinking material, and can thus be transported over greater distances.

\section{Governing Processes for Sediment Transport}

Besides the site-specific sediment transport characteristics, some general findings for near-coastal sediment dynamics can be derived from the presented results. While the average sediment transport direction is determined by the local bathymetry and tidal forcing at a given location, we found that the direction of the contemporaneous wind forcing has by far the largest influence on sediment dispersal. When the effects of tidally and wind-driven sediment transport are counteracting, sediment remains very mobile and is less likely to accumulate at a central position. The tidal variability due to the spring-neap cycle affects the magnitude of transported sediment, but not the general characteristics. A surprising result is the negligible influence of baroclinic effects on sediment transport, although pronounced density differences due to freshwater discharge are observed in the study region. This contrasts earlier findings derived from a 1D model (Schulz and Gerkema 2018), and implies that in regions with very complex topography, like the Wadden Sea, sediment transport is steered by bathymetry, i.e., the orientation of tidal channels and shallow areas, rather than by freshwater effects.

\section{Functioning of the Mud Motor}

The idea of the Mud Motor is to increase the amount of sediment transported toward the salt marsh by changing the disposal location for dredged harbor sediment from a position close to the port to a position at the end of the channel. The relocation of the disposal position is also expected to reduce the recirculation of dredged sediment into the harbor. The model results suggest that the natural currents (flood dominated tide) generally already induce the transport of $70-100 \%$ of the initial 200 tons of dumped sediment toward the salt marshes. Only during some wind conditions are the sediment transport pathways sensitive to the exact disposal location.

In Fig. 9, a visual summary of the model results under different wind forcing is provided. An export of all disposed sediment over the watershed in the northeast can be expected in the presence of wind with sufficient strength from southwesterly and westerly directions (marked red in Fig. 9), which is the prevailing wind direction in this area. The analysis of aerial photographs (see Baptist et al. (2019)) for details revealed that lateral salt marsh growth starts in the northeast, on the side close to the watershed. A transport of sediment from the neighboring basin over the tidal divide with the ebb current could be an explanation for this. Exported sediment is hence not necessarily lost, but could recirculate back toward the salt marsh.

Disposed sediment remains very mobile in the presence of wind from southerly, easterly, or northerly directions (indicated in yellow in Fig. 9). This reduces the accumulation of sediment on the mudflat close to the salt marsh to only $6-41 \%$ of the disposed sediment (northerly and easterly winds), and increases the chances of sediment recirculating into the harbor of Harlingen, especially during wind from northerly to easterly directions.

The best conditions for the Mud Motor (94\% of the sediment dumped at the end of the channel accumulates very close to the salt marsh) are given for wind from the northwest (green in Fig. 9). Under these wind conditions, the location of disposal has a relatively large effect on the sediment spreading (indicated with sketched ships in Fig. 9).

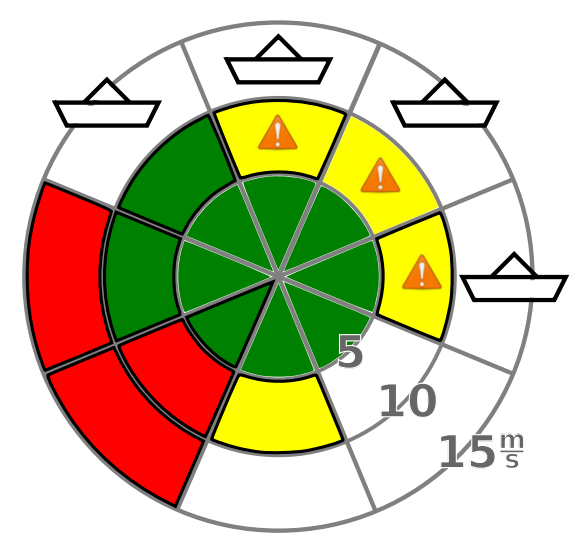

Fig. 9 Schematic visualization of the model results. Red color indicates the export of sediment over the watershed, green stands for possible deposition on the mudflat, and yellow for very mobile sediment. The orange signs indicate wind conditions that promote the possible recirculation of sediment into the harbor; schematized ships indicate wind directions under which the dispersal of sediment is very sensitive to the initial dumping location. Colors with black borders refer to results directly derived from the model results; the others are interpolated 
Consequently, a change of the disposal location to a place further into the channel could be beneficial for sediment accumulation on the salt marsh and reduced recirculation toward the harbor.

\section{Economic Aspects}

The new dumping location for the dredged sediments is $5 \mathrm{~km}$ further away from the harbor, compared with the old dumping site. The additional sailing distance to reach the new location increases the time needed for one dumping cycle by $45 \mathrm{~min}$, from approximately $30-35 \mathrm{~min}$ to $1.3 \mathrm{~h}$. To compensate for the additional sailing time, the dredging company receives an additional 0.85 Euro per cubic meter of dredged sediment (M. Baptist, pers. comm.). Consequently, the costs of one dredging and dumping cycle increase by 510 Euro. With an anticipated annual dredging volume of 369,600 tons (corresponding to roughly 1,000,000 $\mathrm{m}^{3}$ ), the additional costs are in the order of 850,000 Euro/year.

Given that during certain wind conditions, the fate of dumped sediment does not depend on the exact disposal location, it is unnecessary to sail to the new dumping location $68 \%$ of the time. By setting up an optimized dumping schedule that accounts for the wind forecast-using the results from this study-the exact disposal location (old or new) can be chosen dynamically. In this way, unnecessary additional costs and sailing time can be enormously reduced, while the functioning of the Mud Motor remains the same.

\section{Conclusions}

The main conclusion from this study is that the fate of disposed sediments in near-coastal areas is crucially dependent on the contemporaneous wind forcing and, during some wind conditions, also on the initial position of the sediment. Variations in these two factors alone cause the accumulation on the intertidal area to range between 6 and $100 \%$ of the 200 tons of disposed sediment. In this, to our knowledge, unique study, the sensitivity of sediment dispersal to the initial dumping positions and the wind forcing in a complex coastal system are investigated in detail. The presented results show that a synoptic view of the sediment transport patterns in a comparable system can only be achieved by taking into account spatial and temporal variabilities, and especially wind effects. When considering the transport of disposed sediment, the exact disposal location in the system might have a substantial effect on the transport patterns under certain conditions.

The above should be kept in mind when designing a Mud Motor, i.e., when determining a new disposal location for the excessive sediment from maintenance dredging in harbors with the aim to provide frequent sediment nourishment. A new disposal location induces longer sailing time for the dredging ship and leads to increased costs (see "Economic Aspects", Baptist et al. 2019). A prior identification of wind conditions under which disposal at the new location really is beneficial for the aim of the project, like it was performed in this study, can help reduce costs by delivering a simple guideline to decide when to dispose sediment at a new, further away location, depending on the latest weather forecast. Also, an assessment of the regional wind climate is needed to identify how frequent favorable wind conditions occur.

Based on the presented model results and a 10-year wind record (2005 to 2014, see "Study Site"), we can estimate for the Mud Motor region that in $28 \%$ of the time, sediment disposed anywhere in the Kimstergat channel will be transported onto the mudflats. In $23 \%$ of the time, disposed sediment will be exported over the adjacent watershed, again regardless of the exact disposal location in the channel. Wind conditions during which the disposal location is important occur during $32 \%$ of the time. Recirculation to the port could be counteracted by disposal at the new location during those times, but only during $9 \%$ of the (total) time, sediment transport is sensitive to the exact disposal location and wind conditions are also favorable for the accretion of sediment on the mudflat.

A next step to determine how salt marsh growth may be actively supported could be the evaluation of other important physical and biological parameters that govern sediment accretion or erosion on a marsh. For example, wind waves contribute to the erosion of sediment in front of the salt marsh at high wind speeds and could be included in the model. From the biological point of view, large sediment deposition rates are not advantageous during the important initial growth phase of pioneer species like Salicornia spp., which will not grow when seeds are buried below the critical depth of $1 \mathrm{~cm}$ (Regteren et al. 2017). To identify phases of initial growth and to reduce sediment disposal during that time could, among other aspects, further improve the effectiveness of a Mud Motor.

\section{Appendix A: Freshwater discharge effects}

A previous study (Schulz and Gerkema 2018) suggests that transport processes in the investigated Kimstergat channel are influenced by a periodically occurring salinity stratification, caused by the advection of freshwater from the Kornwerderzand (KWZ) sluice, located approximately $10 \mathrm{~km}$ away, during flood phase.

To investigate the influence of freshwater discharge on the hydrodynamic and sediment transport characteristics in the study area, a second set of simulations was run, during 
which the sluice in KWZ was removed from the model domain. To maintain the freshwater budget, the discharge from KWZ was added to that of the second IJsselmeer sluice in Den Oever (see Fig. 1A). All other model parameters remained unchanged.

From comparing the model results analyzed above with those from the second set of simulations without freshwater discharge through the KWZ sluice, it becomes apparent that freshwater effects do not play a significant role for sediment transport in this region under the investigated settings: We found large effects of the sluice discharge on the hydrodynamic properties (e.g., vertical stratification, vertical structure of the residual current) in the study area, but surprisingly, the effects on sediment transport are insignificant. The transport pathways, erosion and deposition patterns, and the timescales remain unchanged in the absence of the sluice discharge, and the quantitative changes are negligible for all simulated scenarios.

This is in line with a previous study: Becherer et al. (2016) state that estuarine circulation, induced by lateral density gradients, only plays a minor role for net transport in the Wadden Sea.

Acknowledgments We like to thank Martin Baptist and the entire MudMotor Team, the crew of the RV Navicula, Eric Wagemaakers, Laura Sandifort, and Jurian Brasser. The authors acknowledge the North-German Supercomputing Alliance (HLRN) for providing required HPC resources, and like to thank the four anonymous reviewers for their constructive suggestions.

Funding Open Access funding enabled and organized by Projekt DEAL. This work was funded by the TTW project "Sediment for the salt marshes: physical and ecological aspects of a mud motor" (grant number 13888). Financial support of K. Klingbeil was provided by the Collaborative Research Centre TRR 181 on Energy Transfers in Atmosphere and Ocean, funded by the German Research Foundation. Financial support of C. Morys was provided by the EMERGO project, which is funded by the Building with Nature program of the NWO division for the Earth and Life Sciences (ALW 850.13.020).

Open Access This article is licensed under a Creative Commons Attribution 4.0 International License, which permits use, sharing, adaptation, distribution and reproduction in any medium or format, as long as you give appropriate credit to the original author(s) and the source, provide a link to the Creative Commons licence, and indicate if changes were made. The images or other third party material in this article are included in the article's Creative Commons licence, unless indicated otherwise in a credit line to the material. If material is not included in the article's Creative Commons licence and your intended use is not permitted by statutory regulation or exceeds the permitted use, you will need to obtain permission directly from the copyright holder. To view a copy of this licence, visit http://creativecommons. org/licenses/by/4.0/.

\section{References}

Baptist, M, T Gerkema, B Van Prooijen, DS Van Maren, M Van Regteren, K Schulz, I Colosimo, J Vroom, T Van Kessel, B
Grasmeijer, P Willemsen, K Elschot, AV De Groot, J Cleveringa, EE Van Eekelen, F Schuurman, HJ De Lange, and ME Van Puijenbroek. 2019. Beneficial use of dredged sediment to enhance salt marsh development applying a Mud Motor. Ecological Engineering 127: 312-323.

Becherer, J, G Flöser, L Umlauf, and H Burchard. 2016. Estuarine circulation versus tidal pumping: Sediment transport in a wellmixed tidal inlet. Journal of Geophysical Research: Oceans 121(8): 6251-6270.

Bridges, TS. 2018. Engineering with Nature - An Atlas. https://doi.org/10.21079/11681/27929.

Bruggeman, J, and K Bolding. 2014. A general framework for aquatic biogeochemical models. Environmental Modelling \& Software 61: 249-265.

Burchard, H, and K Bolding. 2002. GETM - a General Estuarine Transport Model. Scientific Documentation. Tech. Rep. EUR 20253 EN, European Commission.

Burchard, H, Bolding K, and Villarreal MR. 1999. GOTM - a General Ocean Turbulence Model. Theory, implementation and test cases. Tech. Rep. EUR 18745 EN, European Commission.

Canuto, VM, AM Howard, Y Cheng, and MS Dubovikov. 2001. Ocean turbulence. Part I: One-Point closure model - momentum and heat vertical diffusivities. Journal of Physical Oceanography 31: 1413-1426. https://doi.org/10.1175/1520-0485(2001)031 $\langle 1413$ :OTPIOP $\rangle$ 2.0.CO;2.

Colosimo, I, B van Prooijen, B van Maren, and $\mathrm{H}$ Winterwerp. 2017. Reniers A (2017) The importance of wind-induced sediment fluxes on tidal flats. Abstract from INTERCOH Montevideo, Uruguay, pp 53-54.

Donnelly, JP, and MD Bertness. 2001. Rapid shoreward encroachment of salt marsh cordgrass in response to accelerated sea-level rise. Proceedings of the National Academy of Sciences 98(25): 1421814223.

Duran-Matute, M, T Gerkema, GJ De Boer, JJ Nauw, and U Gräwe. 2014. Residual circulation and freshwater transport in the Dutch Wadden sea: a numerical modelling study. Ocean Science 10(4): 611-632.

van Eekelen, E, Baptist M, Dankers P, Grasmeijer B, van Kessel T, and van Maren D. 2016. Muddy waters and the Wadden Sea harbours. In: Proceedings WODCON XXI, Miami, Florida (2016).

Flather, R, and A Davies. 1976. Note on a preliminary scheme for storm surge prediction using numerical models. Quarterly Journal of the Royal Meteorological Society 102(431): 123-132.

Flemming, B, and M Delafontaine. 2000. Mass physical properties of muddy intertidal sediments: some applications, misapplications and non-applications. Continental Shelf Research 20(10-11): 1179-1197.

Flemming, B, and M Delafontaine. 2016. Mass physical sediment properties. Encyclopedia of Estuaries Springer, Dordrecht, pp 419-432.

Gatto, VM, BC van Prooijen, and ZB Wang. 2017. Net sediment transport in tidal basins: quantifying the tidal barotropic mechanisms in a unified framework. Ocean Dynamics 67(11): 1385-1406.

Gerkema, T, and M Duran-Matute. 2017. Interannual variability of mean sea level and its sensitivity to wind climate in an inter-tidal basin. Earth System Dynamics 8(4): 1223-1235.

Gräwe, U, G Flöser, T Gerkema, M Duran-Matute, TH Badewien, E Schulz, and H Burchard. 2016. A numerical model for the entire Wadden sea: skill assessment and analysis of hydrodynamics. Journal of Geophysical Research: Oceans 121(7): 5231-5251.

Hamm, L, M Capobianco, H Dette, A Lechuga, R Spanhoff, and M Stive. 2002. A summary of European experience with shore nourishment. Coastal Engineering 47(2): 237-264.

Hanson, H, A Brampton, M Capobianco, H Dette, L Hamm, C Laustrup, A Lechuga, and R Spanhoff. 2002. Beach nourishment 
projects, practices, and objectives - a European overview. Coastal Engineering 47(2): 81-111.

Jay, DA, and JD Musiak. 1994. Particle trapping in estuarine tidal flows. Journal of Geophysical Research:, Oceans 99(C10): 20445-20461.

Keijsers, JG, A Poortinga, MJ Riksen, and J Maroulis. 2014. Spatiotemporal variability in accretion and erosion of coastal foredunes in the netherlands: Regional climate and local topography. PloS one 9(3): e91115.

Klingbeil, K, M Mohammadi-Aragh, U Gräwe, and H Burchard. 2014. Quantification of spurious dissipation and mixing - Discrete Variance Decay in a Finite-Volume framework. Ocean Modelling 81: 49-64. https://doi.org/10.1016/j.ocemod.2014.06.001.

Klingbeil, K, F Lemarié, L Debreu, and H Burchard. 2018. The numerics of hydrostatic structured-grid coastal ocean models: state of the art and future perspectives. Ocean Modelling 125: 80-105. https://doi.org/10.1016/j.ocemod.2018.01.007.

Lettmann, KA, JO Wolff, and TH Badewien. 2009. Modeling the impact of wind and waves on suspended particulate matter fluxes in the East Frisian Wadden Sea (southern North Sea). Ocean Dynamics 59(2): 239-262.

Manning, AJ, JV Baugh, JR Spearman, and RJ Whitehouse. 2010. Flocculation settling characteristics of mud: sand mixtures. Ocean dynamics 60(2): 237-253.

Manning, AJ, JV Baugh, JR Spearman, EL Pidduck, and RJ Whitehouse. 2011. The settling dynamics of flocculating mudsand mixtures: Part 1 - Empirical algorithm development. Ocean Dynamics 61(2-3): 311-350.

Nasermoaddeli, MH, C Lemmen, G Stigge, O Kerimoglu, H Burchard, K Klingbeil, R Hofmeister, M Kreus, KW Wirtz, and F Kösters. 2018. A model study on the large-scale effect of macrofauna on the suspended sediment concentration in a shallow shelf sea. Estuarine: Coastal and Shelf Science.

Nordstrom, K. 2005. Beach nourishment and coastal habitats: research needs to improve compatibility. Restoration Ecology 13(1): 215222.

Purkiani, K, J Becherer, K Klingbeil, and H Burchard. 2016. Windinduced variability of estuarine circulation in a tidally energetic inlet with curvature. Journal of Geophysical Research: Oceans 121(5): 3261-3277.

Regteren, M, R Boer, E Meesters, and A Groot. 2017. Biogeomorphic impact of oligochaetes (Annelida) on sediment properties and Salicornia spp. seedling establishment (2017), Ecosphere, 8, 7.

Reise, K, Baptist M, Burbridge P, Dankers N, Fischer L, Flemming B, Oost A, and Smit C. 2010. The wadden sea-a universally outstanding tidal wetland. In: The Wadden Sea 2010. Common Wadden Sea Secretariat (CWSS); Trilateral Monitoring and
Assessment Group: Wilhelmshaven. (Wadden Sea Ecosystem; 29/editors, H. Marencic and J. de Vlas), vol 7.

Ridderinkhof, H, and J Zimmerman. 1992. Chaotic stirring in a tidal system. Science 258(5085): 1107-1111.

Sassi, M, M Duran-Matute, T van Kessel, and T Gerkema. 2015. Variability of residual fluxes of suspended sediment in a multiple tidal-inlet system: the Dutch Wadden Sea. Ocean Dynamics 65(910): 1321-1333.

Sassi, MG, T Gerkema, M Duran-Matute, and JJ Nauw. 2016. Residual water transport in the Marsdiep tidal inlet inferred from observations and a numerical model. Journal of Marine Research 74(1): 21-42.

Schindler, RJ, DR Parsons, L Ye, JA Hope, JH Baas, J Peakall, AJ Manning, RJ Aspden, J Malarkey, S Simmons, and et al. 2015. Sticky stuff: Redefining bedform prediction in modern and ancient environments. Geology 43(5): 399-402.

Schulz, K, and T Gerkema. 2018. An inversion of the estuarine circulation by sluice water discharge and its impact on suspended sediment transport. Estuarine, Coastal and Shelf Science 200: $31-40$.

Simpson, JH, J Brown, J Matthews, and G Allen. 1990. Tidal straining, density currents, and stirring in the control of estuarine stratification. Estuaries and Coasts 13(2): 125-132.

Speybroeck, J, D Bonte, W Courtens, T Gheskiere, P Grootaert, JP Maelfait, M Mathys, S Provoost, K Sabbe, EW Stienen, V van Lancker, M Vincx, and S Degraer. 2006. Beach nourishment: an ecologically sound coastal defence alternative? a review. Aquatic Conservation:, Marine and Freshwater Ecosystems 16(4): 419-435.

Tolhurst, T, Gust G, and Paterson D. 2002. The influence of an extracellular polymeric substance (EPS) on cohesive sediment stability. In: Proceedings in marine science, vol 5, Elsevier, pp 409-425.

Umlauf, L, and H Burchard. 2005. Second-order turbulence closure models for geophysical boundary layers. a review of recent work. Continental Shelf Research 25(7): 795-827.

Van Kessel, T, H Winterwerp, B Van Prooijen, M Van Ledden, and W Borst. 2011. Modelling the seasonal dynamics of spm with a simple algorithm for the buffering of fines in a sandy seabed. Continental Shelf Research 31(10): 124-134.

Wiegman, N, R Perluka, S Oude Elberink, and Vogelzang J. 2005. (2005) vaklodingen: de inwintechnieken en hun combinaties. Vergelijking tussen verschillende inwintechnieken en de combinaties ervan. ["Vaklodingen" (bathymetric surveys): data collection techniques and their combinations.] AGI-rapport.

Publisher's Note Springer Nature remains neutral with regard to jurisdictional claims in published maps and institutional affiliations. 